\title{
É COISA DE MENINA: uma iniciativa para atrair meninas de escolas públicas em áreas de risco para cursos de Ciência, Tecnologia, Engenharias e Matemática
}

\author{
Victoria Santana $^{1}$, Katia da Silva ${ }^{1}$, Gabrielly Freitas ${ }^{1}$, Isabelle de Oliveira ${ }^{1}$, Igor \\ Brito ${ }^{1}$ \\ ${ }^{1}$ Universidade Federal Rural do Semi-Árido (UFERSA) \\ Rua Francisco Mota Bairro, 572 - Pres. Costa e Silva, 59625-900 - , Mossoró - RN - \\ Brasil \\ \{victoria.santana, katiacs\}@ufersa.edu.br, \{gabrielly.cs, \\ pdo.isabelle\}@gmail.com, igo.brito@hotmail.com.br
}

\begin{abstract}
This article subscribes to the topics of Informatics in Education and Computational Logic and describes a project to be developed in peripheral zone schools of the Mossoró's State Teaching Network. The objective is to motivate girls in dangerous situations to pursue a scientific career, to ingress into a bachelor in the field of Science, Technology, Engineering or Math, through the teaching of programming logic to girls in the final years of the fundamental years, through an extension Project of direct intervention. We aim, as results, to motivate the permanence of girls in school, as well as the development of skills and competences that make easier the insertion of them in scientific careers.
\end{abstract}

Resumo. Este artigo se inscreve nos tópicos de Informática na Educação e Lógica Computacional e descreve um projeto a ser desenvolvido em escolas periféricas da Rede Pública Estadual de Educação Básica da cidade Mossoró. Objetiva motivar as meninas em situação de risco a optarem por carreiras científicas, nos cursos de graduação em Ciência, Tecnologia, Engenharias ou Matemática, através do ensino de lógica de programação para meninas do Ensino Fundamental II, através de um projeto de extensão de intervenção direta. Pretende-se, como resultados, motivar a permanência das meninas na escola, bem como o desenvolvimento de habilidades e competências que facilitem a inserção destas em carreiras científicas.

\section{Introdução}

Historicamente, as áreas de Ciência, Tecnologia, Engenharias e Matemática (STEM Science, Technology, Engineering and Mathematics) são dominadas por homens. A teoria mais aceita, que tenta explicar esse fenômeno, é a de que a socialização das crianças baseada em gênero [Vianna e Finco, 2009] é responsável por isso, pois enquanto os meninos são estimulados a construir coisas e a pensar logicamente, as meninas são compelidas a utilizar brinquedos passivos e que incentivam cuidado e organização. Esse comportamento é comprovadamente nocivo à ambos os gêneros; todavia decidimos focar nas meninas visto que existem estudos que apontam que os alunos do gênero masculino são mais estimulados a desenvolverem e seguirem nas áreas STEM, inclusive sendo preferidos e bonificados por professores das ciências exatas e matemática [Queiroz et. al, 2014]. 
A motivação para o desenvolvimento do projeto a ser descrito neste artigo parte da observação da realidade das crianças em escolas públicas de áreas periféricas. Muitas delas, além de estudar, também ajudam em casa, ou trabalham e, em casos extremos, se envolvem no crime e largam os estudos. Diante disso, nasceu a ideia de um projeto que fomente o interesse de meninas de escolas periféricas pelas áreas STEM, por meio de um projeto de extensão a ser realizada por alunas e professoras do Departamento de Computação da UFERSA.

O projeto será desenvolvido em duas escolas públicas, durante dois anos, contando com uma equipe multidisciplinar, composta por estudantes de Ciência da Computação, Psicologia e Serviço Social, bem como por docentes/pesquisadores com reconhecida experiência em projetos educacionais de intervenção nas Redes Públicas de Ensino Básico; todos oriundos das instituições parceiras no desenvolvimento do projeto.

\section{Contexto de desenvolvimento da pesquisa}

Do último censo da educação superior lançado pela Sociedade Brasileira de Computação (SBC) em 2018, mas com dados referentes a 2016 e anos anteriores, temos a seguinte estatística referente ao gênero dos ingressantes nos cursos de computação: $54,5 \%$ de homens e 45,5\% de mulheres, matriculados em cursos superiores no Brasil [SBC, 2018].

Apesar de no ano de 2016 ter ocorrido um salto no número de mulheres ingressando nos cursos de computação, há de se notar que nos anos anteriores estava havendo uma queda na quantidade de mulheres. Também é notória a discrepância entre quantidade de homens e mulheres que concluem os cursos.

Dos dados do Resumo Técnico do Índice de Desenvolvimento da Educação Básica (IDEB) [INEP, 2017], temos que a educação básica no Rio Grande do Norte está abaixo da média nacional, especificamente a rede estadual de ensino, que é nosso foco de ação neste projeto.

Unindo esses dois dados buscamos executar um projeto de relevância, tanto para aumentar a quantidade de mulheres nas áreas de exatas (a longo prazo) quanto para melhorar os índices do nosso estado (a curto prazo).

\section{Experiências exitosas}

Não é nova a ideia de iniciativas para atrair mulheres para a computação ou muito menos a de levar atividades extracurriculares para áreas de risco como forma de incentivar as crianças e jovens a se dedicarem aos estudos e não tomar parte em atividades ilícitas. A Sociedade Brasileira de Computação por meio do programa Meninas Digitais [Maciel e Bim, 2017] conta com várias iniciativas espalhadas pelo Brasil, projetos de extensão universitária trabalhando em escolas de ensino fundamental e médio para tornar a computação acessível e interessante a todas.

\section{Proposta de intervenção}

O objetivo principal é mostrar às meninas que elas podem ter carreiras em áreas que, talvez, nunca imaginaram ou tenham sido estimuladas a seguir; não só em Ciência da Computação, como também em outras carreiras científicas.

Sabendo da realidade das comunidades nas quais vamos implantar o projeto, as 
quais muitas vezes não tem suporte a informática, foi proposto como método o CS Unplugged - Computação Desplugada - que, como o nome sugere, promove o ensino da ciência da computação sem o uso de computadores, por meio de atividades lúdicas e de resolução de problemas.

Durante dois anos trabalharemos em duas escolas públicas, dois dias na semana dedicados às atividades com as meninas, no contraturno das aulas regulares da escola, mas não ocupando a tarde toda para não atrapalhar a rotina das meninas.

As ações pretendidas fazem parte das orientações contidas na Agenda Global da Educação 2030, contemplando 3 das 4 categorias de ação propostas: intervenções de âmbito individual, de âmbito escolar e de âmbito social [Unesco, 2018].

\subsection{Ações pretendidas}

Buscamos a educação de forma prática, imersiva e lúdica, com intuito de estimular a inclinação para as áreas de exatas, o raciocínio lógico e a solução de problemas. Para tanto, nos encontros, teremos atividades como criação de jogos de tabuleiro, hackathons com premiações, leitura e encenação dos cenários femininos na ciência, dinâmicas, solução de puzzles, entre outras formas de encorajar a interação entre as alunas e a identificação com as áreas STEM.

\section{Resultados esperados}

Objetivamente, ao fim do projeto, buscaremos observar a diminuição na evasão escolar por parte das meninas nele envolvidas e a melhora no desempenho das alunas nas disciplinas que envolvem matemática e raciocínio lógico. No campo sociológico e humanitário, visamos perceber que as meninas e a comunidade na qual estão inseridas passem a ter nas ciências exatas uma opção viável de carreira e futuro, assim enviesando-se ao mundo do STEM e quebrando paradigmas enraizados.

\section{Considerações finais}

A luz da intenção de que o projeto sirva para atrair mais mulheres para as áreas de exatas, o projeto não para nessa ação de ensino fundamental. Buscaremos expandir para outros níveis de ensino, como o fundamental I (anos iniciais) e ensino médio a fím de atingir mais meninas e manter o interesse delas nos assuntos referentes à computação; com esses objetivos podemos inserir as meninas em competições e feiras de ciências, as quais existem em nível nacional e internacional. Essa integração a outros eventos e ambientes é benéfica pois é estimulante e traz boa repercussão a todas as entidades envolvidas.

\section{Referencias}

Vianna, C. and Finco, D. (2009). Meninas e meninos na Educação Infantil: uma questão de gênero e poder. Cadernos Pagu, n. 33, p. 265-283.

Queiroz, C. De, Carvalho, M. De and Aires, J. (2014). Gênero e inclusão de jovens mulheres nas ciências exatas, nas engenharias e na computação. 18 Redor, n. 2010, p.

$3483-3500$. 
Maciel, C. and Bim, S. A. (2017). Programa Meninas Digitais - ações para divulgar a Computação para meninas do ensino médio. Anais do Computer on the Beach, v. 0, n. 0, p. 327-336.

Sociedade Brasileira de Computação - SBC (2018). Educação Superior em Computação Estatísticas-2016.

INSTITUTO NACIONAL DE ESTUDOS E PESQUISAS EDUCACIONAIS ANÍSIO TEIXEIRA. Resumo técnico do Ideb. Brasília: Inep (2017).

UNESCO. Decifrar o código: educação de meninas e mulheres em ciências, tecnologia, engenharia e matemática (STEM). Brasília: UNESCO, 2018. 84p. 